\title{
ATIVIDADE ANTIMICROBIANA DA ERVA-MATE (Ilex paraguariensis) CONTRA MICRORGANISMOS ISOLADOS DA CARNE DE FRANGO
}

\author{
ANTIMICROBIAL ACTIVITY OF YERBA MATE (Ilex paraguariensis) \\ EXTRACT AGAINST MICROORGANISMS ISOLATED FROM CHICKEN \\ MEAT
}

\author{
Débora Euclydes Mariano Costa ${ }^{1^{*}}$ \\ Aline Mondini Calil Racanicci ${ }^{1}$ \\ Ângela Patrícia Santana ${ }^{1}$ \\ ${ }^{1}$ Universidade de Brasília, Brasília, DF, Brasil. \\ *Autora para correspondência - debora45@gmail.com
}

\section{Resumo}

A erva-mate vem sendo estudada devido às diversas atividades biológicas já evidenciadas. Este estudo teve como objetivo avaliar o efeito antimicrobiano, pelo método de difusão em disco, da adição de extratos de erva-mate frente à Escherichia coli e ao Proteus mirabilis previamente isolados da carne de peito de frango. Foram utilizadas diferentes concentrações de extrato (125 $\mathrm{mg} / \mathrm{mL}, 250 \mathrm{mg} / \mathrm{mL}, 550 \mathrm{mg} / \mathrm{mL}$ de extrato de erva-mate, controle negativo com solução salina $0,85 \%$ e erva-mate pura) em triplicata e os resultados analisados pelo SAS $^{\circledR} 5.1$. Quanto maior a concentração de extrato aplicada, maior $(\mathrm{P}<0,0001)$ foi o halo de inibição formado para as duas bactérias avaliadas, sendo que para a $E$. coli os halos foram menores quando comparados com os halos para o P. Mirabilis. Foi possível estimar a concentração de $400 \mathrm{mg} / \mathrm{mL}$ como sendo a mais eficiente frente ambas as bactérias avaliadas.

Palavras-chave: Antimicrobiano natural; erva-mate; Escherichia coli; Proteus mirabilis.

\begin{abstract}
Yerba mate has been studied due to the biological activities already evidenced. This study aimed to evaluate the antimicrobial effect of the addition of yerba mate extracts against Escherichia coli and Proteus mirabilis previously isolated from chicken breast meat using the disk diffusion method. Different extract concentrations were applied $(125 \mathrm{mg} / \mathrm{mL}, 250 \mathrm{mg} / \mathrm{mL}, 550 \mathrm{mg} / \mathrm{mL}$ of yerba mate extract, negative control with saline $0.85 \%$ and pure yerba mate) in triplicate and the results were analyzed by the $\mathrm{SAS}^{\circledR} 5.1$. The increase in the concentration of the extract applied resulted in an increase $(\mathrm{P}<0.0001)$ in the inhibition zone formed for both bacteria, and it was evident that the inhibition zone for $E$. coli was smaller compared with the halos for P. mirabilis. It was possible to estimate the concentration of $400 \mathrm{mg} / \mathrm{mL}$ as the most efficient for both bacteria.
\end{abstract}

Keywords: Escherichia coli; natural antimicrobial; Proteus mirabilis; yerba mate. 


\section{Introdução}

Nos últimos anos, a atividade antibacteriana de extratos de plantas tem sido objeto de várias pesquisas $^{(1-4)}$, uma vez que o interesse pela utilização de plantas como antimicrobianos naturais por parte dos consumidores vem aumentando devido à crescente rejeição do uso de produtos sintéticos $^{(5)}$. Diversos trabalhos têm demonstrado a atividade antimicrobiana in vitro ou em alimentos da adição de vários produtos de origem vegetal, tais como os extratos de orégano, ervamate, alecrim, ginseng, gengibre, caqui, laranja, limão, alho entre outros, revelando, assim, possíveis substitutos aos antimicrobianos sintéticos utilizados nas indústrias de alimentos ${ }^{(4,6-11)}$. As bactérias gram-negativas, entretanto, são geralmente menos sensíveis à ação antimicrobiana dos compostos bioativos de plantas devido à presença da membrana lipopolissacarídea, que restringe a difusão de compostos hidrofóbicos ${ }^{(12)}$.

A Ilex paraguariensis é uma planta da família Aquifoliaceae, conhecida popularmente como ervamate $^{(13)}$, produzida e comercializada principalmente no Brasil, Uruguai, Paraguai e Argentina ${ }^{(14)}$. No Brasil, o cultivo e colheita da planta se dão pelo extrativismo da floresta natural ou pelo sistema misto, em que se combina o crescimento da floresta com melhores práticas de cultivo ${ }^{(15)}$.

A composição química do gênero Ilex é variável, sendo que os principais constituintes encontrados nessa planta são as xantinas, as saponinas e os compostos fenólicos, como ácidos fenólicos, derivados do cafeoil e flavonoides ${ }^{(15,16)}$. A Ilex paraguariensis possui maiores concentrações dos derivados de cafeoil, como o ácido clorogênico e o ácido caféico, e de flavonoides, como a rutina e a quercetina, quando comparada com outras espécies do gênero Ilex ${ }^{(17)}$. O ácido caféico presente na erva-mate, juntamente com os flavonoides, apresenta atividade antimicrobiana frente a bactérias, fungos e vírus ${ }^{(5,18)}$.

Além desses compostos, os polifenóis encontrados na erva-mate, como a cafeína, derivados do cafeoil, ácido clorogênico, quercitinas, rutinas e teobrominas, contribuem para a atividade antimicrobiana contra patógenos de origem alimentar ${ }^{(16)}$. Estudos utilizando extratos de erva-mate vêm demonstrando efeito antimicrobiano in vitro frente a diversos microrganismos como Streptococcus mutans, Streptococcus sobrinus, Listeria monocytogenes ${ }^{(3)}$, Candida albicans, Proteus mirabilis, Pseudomonas aeruginosa, Staphylococcus aureus e Staphylococcus epidermidis $^{(1)}$, Salmonella enteritidis, Salmonella Lexigton, Salmonella derby, Salmonella enterica e Salmonella infantis ${ }^{(19)}$, Enterococcus faecalis ${ }^{(20)}$, Shigella sonnei ${ }^{(21)}$ e Escherichia coli ${ }^{(22)}$.

O objetivo deste estudo foi investigar o efeito da adição de diferentes concentrações de extrato de erva-mate sobre a inibição de microorganismos isolados da carne de peito de frango.

\section{Materiais e Métodos}

O extrato liofilizado de erva-mate (Ilex paraguariensis A. St.-Hil.) foi obtido por extração com água $(65-85 \%)$ e etanol (15-35\%) a partir das folhas das plantas, sem a adição de nenhum conservante (Centro Flora, Botucatu/SP). Uma amostra ( $25 \mathrm{~g})$ do extrato foi submetida à avaliação 
da sua condição microbiológica inicial, em triplicata, através do número mais provável (NMP) de coliformes totais e coliformes termotolorantes, da contagem padrão de bactérias mesofílicas totais, da contagem de bactérias psicotróficas, da contagem de bolores e leveduras e da pesquisa da presença de Staphylococcus sp. e de Salmonella sp, segundo o protocolo de Silva et al. ${ }^{(23)}$ e as normas do Ministério da Agricultura Pecuária e Abastecimento ${ }^{(24)}$.

Para a avaliação da atividade antimicrobiana do extrato de erva-mate foi realizado o teste de difusão em disco, conforme os procedimentos descritos pelo National Committee for Clinical Laboratory Standards (NCCLS). Os discos foram preparados utilizando-se papel filtro (marca Framex) com 6 $\mathrm{mm}$ de diâmetro, que foram cortados e autoclavados para garantia da esterilidade. Os discos de papel filtro receberam $10 \mu \mathrm{L}$ das diluições dos diferentes tratamentos utilizados, que foram: $\mathrm{CN}$ controle negativo (solução salina 0,85\%), 125 (adição de $125 \mathrm{mg}$ de extrato de erva-mate/mL), 250 (250 mg de extrato de erva-mate/mL), 550 (550 mg de extrato de erva-mate/mL) e puro (extrato de erva-mate puro). As concentrações aplicadas foram obtidas pela diluição do extrato em solução salina $0,85 \%$ e homogeneizadas com um agitador de tubos tipo Vortex, exceto para o tratamento com erva-mate pura, em que o disco foi umedecido em solução salina $0,85 \%$ e envolto pelo extrato em forma de pó. Após a aplicação dos tratamentos, os discos foram incubados a $36{ }^{\circ} \mathrm{C}\left( \pm 1{ }^{\circ} \mathrm{C}\right)$ por 36 horas para secagem e armazenados lacrados a $7^{\circ} \mathrm{C}$ até o dia das análises.

Cepas de Proteus mirabilis e de Escherichia coli de amostras de carne de peito de frango, previamente isoladas e identificadas com o auxílio de meios de cultura seletivos, microscopia e provas bioquímicas, além de teste sorológico no caso da $E$. coli, foram utilizadas para o estudo da atividade antimicrobiana do extrato de erva-mate. As duas bactérias foram semeadas em ágar nutriente por 24 horas a $37{ }^{\circ} \mathrm{C}$, suspensas em solução salina $0,85 \%$ e incubadas a $35^{\circ} \mathrm{C}$ até alcançar turbidez de 0,5 da escala padrão de McFarland.

Com o auxílio de $s w a b$ estéril, o inóculo foi semeado de maneira uniforme por toda a superfície da placa de ágar Müeller-Hinton. Foram adicionados três a quatro discos dos diferentes tratamentos em cada placa semeada, em triplicata. As placas semeadas e contendo os discos foram invertidas e incubadas a $36 \pm 1{ }^{\circ} \mathrm{C}$ por cerca de 18 horas. $\mathrm{O}$ halo de inibição foi considerado como a área sem crescimento detectável a olho nu e os diâmetros dos halos de inibição foram mensurados em milímetros, incluindo o diâmetro do disco. O resultado final de cada tratamento foi obtido pela média das três repetições, sendo considerados suscetíveis, os halos com diâmetro igual ou acima de $10 \mathrm{~mm}$.

O delineamento experimental utilizado foi inteiramente casualizado, com cinco tratamentos e três repetições. Os dados foram submetidos à análise de variância (GLM) utilizando-se software estatístico SAS ${ }^{\circ}$ 5.1. Os resultados dos halos de inibição, com exceção do tratamento com ervamate pura (puro), foram submetidos à análise de regressão por meio do PROC REG do software estatístico $\mathrm{SAS} \circledast 5.1$. As médias entre os tratamentos foram comparadas pelo teste de Tukey, com o nível de significância de 5\%. 


\section{Resultados e Discussão}

Nas avaliações efetuadas nas amostras de extrato de erva-mate não foi detectado crescimento de microrganismos, sendo esse produto considerado livre de contaminação bacteriana e fúngica para as análises efetuadas.

A aplicação do extrato de erva-mate nos discos provocou inibição do crescimento microbiano, uma vez que foi verificada diferença significativa $(\mathrm{P}<0,05)$ entre as médias dos diâmetros dos halos encontrados para as duas bactérias avaliadas (Tabela 1). Tanto para E. coli como para P. mirabilis, quanto maior a concentração do extrato de erva-mate aplicado, maior foi o halo de inibição obtido, assim como foi verificado por Biasi et al. ${ }^{(1)}$, também utilizando extrato de erva-mate.

Tabela 1. Resultados médios da atividade antimicrobiana das diferentes concentrações de extrato de erva-mate frente à $E$. coli e ao $P$. mirabilis

\begin{tabular}{ccc}
\hline $\begin{array}{c}\text { Concentração do extrato } \\
(\mathbf{m g} / \mathbf{m l})\end{array}$ & \multicolumn{2}{c}{ Halo de inibição (mm) } \\
$\mathbf{C N}$ & $\boldsymbol{E}$. coli $^{-}$ & $\boldsymbol{P}$. mirabilis \\
\cline { 2 - 3 } $\mathbf{1 2 5}$ & $0,00^{\mathrm{D}}$ & $0,00^{\mathrm{D}}$ \\
$\mathbf{2 5 0}$ & $10,99^{\mathrm{C}}$ & $20,21^{\mathrm{C}}$ \\
$\mathbf{5 5 0}$ & $12,44^{\mathrm{BC}}$ & $22,33^{\mathrm{BC}}$ \\
$\mathbf{P u r o}$ & $13,99^{\mathrm{AB}}$ & $23,88^{\mathrm{B}}$ \\
$\mathbf{P}$ & $14,99^{\mathrm{A}}$ & $27,77^{\mathrm{A}}$ \\
$\mathbf{C V}$ & $<0,0001^{1}$ & $<0,0001^{\mathbf{2}}$ \\
& 6,50 & 5,64 \\
\hline
\end{tabular}

CV: Coeficiente de variação (\%)

A.B.C Médias seguidas por letras distintas na coluna diferem entre si pelo Teste de Tukey $(\mathrm{P}<0,05)$.

$\mathrm{Y}^{1}=0,81699+0,07656 \mathrm{x}-0,00009630 \mathrm{x}^{2} / \mathrm{R}^{2}=0,9312$

$\mathrm{Y}^{2}=1,55042+0,13997 \mathrm{x}-0,00018191 \mathrm{x}^{2} / \mathrm{R}^{2}=0,9228$

Os diâmetros dos halos de inibição formados pela ação do extrato de erva-mate foram maiores para P. mirabilis em comparação com os encontrados para E. coli; todavia, foi possível notar que mesmo a menor concentração de extrato demonstrou atividade frente às duas bactérias, em relação ao $\mathrm{CN}$. De forma semelhante, Vaquero et al. ${ }^{(25)}$ e Burris et al. ${ }^{(22)}$ também observaram efeito antimicrobiano dos extratos de Ilex paraguariensis frente a E. coli e P. mirabilis ${ }^{(1)}$. Por outro lado, ao utilizar o extrato hidro-alcóolico de erva-mate na concentração de $10 \%$ frente às mesmas bactérias pelo método de difusão em disco, Gonçalves et al. ${ }^{(21)}$ não encontraram efeito antibacteriano, assim como 
Biasi et al. ${ }^{(1)}$ e Carelli et al. ${ }^{(26)}$.

A divergência dos resultados encontrados quanto à sensibilidade dos microrganismos frente aos extratos naturais das plantas pode ocorrer por diversos fatores, tais como a parte da planta utilizada, a época da colheita, o método de extração e a exposição ou não dessa planta ao sol ${ }^{(1,27)}$, fatores que estão diretamente relacionados à concentração dos compostos bioativos presentes nos extratos.

Neste estudo, foi possível observar também regressões de segundo grau significativas $(\mathrm{P}<0,0001)$ entre os níveis crescentes de extrato de erva-mate, tanto para a E. coli quanto para o $P$. mirabilis. Neste caso, quanto maior a concentração do extrato aplicado, maior foi o halo de inibição formado para as duas bactérias analisadas, até atingir o ponto de inflexão, que foi de $398 \mathrm{mg}$ de extrato de erva-mate $/ \mathrm{mL}$ para a $E$. coli e de $385 \mathrm{mg}$ de extrato de erva-mate $/ \mathrm{mL}$ para $P$. mirabilis. Portanto, foi possível estimar em $400 \mathrm{mg} / \mathrm{mL}$ de extrato de erva-mate a concentração mais eficiente frente ambas as bactérias avaliadas.

Apesar das duas bactérias isoladas da carne de frango terem demonstrado sensibilidade frente ao extrato de erva-mate utilizado, isso não significa necessariamente que este extrato possa também apresentar efeito antimicrobiano quando aplicado diretamente sobre a carne. O efeito inibitório de antimicrobianos naturais sobre o crescimento de bactérias deteriorantes típicas de carne suína foi investigado em outro estudo ${ }^{(28)}$. Os autores determinaram a concentração inibitória mínima (MIC) dos antimicrobianos frente aos microrganismos isolados da carne e, posteriormente, os aplicaram na carne suína embalada a vácuo no intuito de avaliar o efeito na sua preservação. Entretanto, eles verificaram que concentrações de até 10 vezes os valores do MIC não afetaram o crescimento microbiológico na carne suína. Segundo os autores, esse fato pode ser devido à dificuldade de movimentação dos compostos antimicrobianos através da porção lipídica das membranas, proteínas ou carboidratos, diferenças nas atividades da água, interações entre espécies bacterianas ou mudanças nas bactérias que as tornaram menos suscetíveis aos antimicrobianos em alimentos.

Embora este estudo não tenha efetuado a avaliação sensorial do extrato de erva-mate na carne, outros autores o fizeram. Racanicci et al. ${ }^{(29)}$ avaliaram sensorialmente almôndegas de carne de frango adicionadas de 0,05 ou $0,1 \%$ do extrato aquoso ou folhas secas de erva-mate. Os autores verificaram que a adição de $0,05 \%$ não afetou o aroma nem o sabor dos produtos cárneos. A adição de $0,1 \%$ do extrato aquoso alterou o aroma e a adição de $0,1 \%$ de folhas secas alterou tanto o sabor quanto o aroma; entretanto, a alteração no sabor do produto não foi considerada um aspecto negativo pelo painel sensorial.

\section{Conclusão}

$\mathrm{O}$ extrato de erva-mate estudado apresentou atividade antimicrobiana frente à $E$. coli e o $P$. mirabilis in vitro, sugerindo boas perspectivas para a utilização deste extrato como antimicrobiano natural, sendo recomendada a concentração de $400 \mathrm{mg}$ de extrato/mL para inibir o crescimento das bactérias estudadas. 


\section{Referências}

1. Biasi B, Grazziotin NA, Hofmann jr AE. Atividade antimicrobiana dos extratos de folha e ramos da Ilex paraguariensis A. St.-Hil., Aquifoliaceae. Revista Brasileira de Farmacolognosia. 2009; 19 (2b): 582-585.

2. Bendahou M, Muselli A, Dubois-Grignon M, Benyoucef M, Desjobert JM, Bernardini AF, Costa J. Antimicrobial activity and chemical composition of Origanum glandulosum Desf. essential oil and extract obtained by microwave extraction: Comparison with hydrodistillation. Food Chemistry. 2008; 106: 132-139.

3. Oh J, Jo H, Cho AR, Kim SJ, Han J. Antioxidant and antimicrobial activities of various leafy herbal teas. Food Control. 2013; 31: 403-409.

4. Krishnan KR, Babuskina S, Babu PAS, Sasikala M, Sabina K, Archana G, Sivarajan M, Sukumar M. Antimicrobial and antioxidant effects of spice extracts on the shelf life extension of raw chicken meat. International Journal of Food Microbiology. 2014; 171: 32-40.

5. Cowan MM. Plant Products as Antimicrobial Agents. Clinical Microbiology Reviews. 1999; 12 (4): 564582 .

6. Yin M, Cheng W. Antioxidant and antimicrobial effects of four garlic-derived organosulfur compounds in ground beef. Meat Science. 2003; 63: 23-28.

7. López JF, Zhi N, Aleson-Carbonell L, Pérez-Alvarez JA, Kuri V. Antioxidant and antibacterial activities of natural extracts: application in beef meatballs. Meat Science. 2005; 69: 371-380.

8. Milani LIG, Terra NN; Fries LLM, Rezer APS, Ferreira SF, Cichoski AJ, Valente CRF. Oxidação lipídica, características sensoriais e cor da carne de frango adicionada de extratos de caqui (Diospyros kaki, L.) e submetida a tratamento térmico. Brazilian Journal of Food Technology. 2010; 13 (4): 242-250.

9. Ibrahim HM, Abou-Arab AA, Salem FM. A. Antioxidant and antimicrobial effects of some natural plant extracts added to lamb patties during storage. Grasas y Aceites. 2011; 62 (2): 139-148.

10. Martin JGP, Porto E, Alencar SM, Glória EM, Corrêa CB, Cabral ISR. Antimicrobial activity of yerba mate (Ilex paraguariensis St. Hil.) against food pathogens. Revista Argentina de Microbiologia. 2013; 45 (2): 93-98.

11. Burris KP, Higginbotham KL, Stewart Jr CN. Aqueous extracts of yerba mate as bactericidal agents against methicillin-resistant Staphylococcus aureus in a microbiological medium and ground beef mixtures. Food Control. 2015; 50: 748-753.

12. Tajkarimi MM, Ibrahim SA, Cliver DO. Antimicrobial herb and spice compounds in food. Food Control. 2010; 21: 1199-1218.

13. Lorenzi H, Matos FJA.Plantas Medicinais no Brasil, nativas e exóticas. 2ed. Instituto Plantarum de Estudos da Flora LTDA; 2008; 90-91.

14. Bracesco A, Sanchez AG, Contreras V, Menini T, Gugliucci A. Recent advances on Ilex paraguariensis research: Minireview. Journal of Ethnpharmacology. 2011; 136: 378-384.

15. Heck CI, De Mejía EG. Yerba mate tea (Ilex paraguariensis): a comprehensive review on chemistry, helth implications, and technological considerations. Journal of food Science. 2007; 72 (9): 138-151.

16. Burris KP, Harte FM, Davidson PM, Stewart CN, Zivanovic S. Composition and bioactive properties of yerba mate (Ilex paraguariensis A. St.-Hil.): A review. Chilean Journal of Agricultural Research. 2012; 72 (2): 268-274.

17. Filip R, Lopez P, Giberti G, Coussio J, Ferraro G. Phenolic compounds in seven South American Ilex 
species. Fitoterapia. 2001; 72: 774-778.

18. Cushnie TPT, Lamb AJ. Antimicrobial activity of flavonoids. International Journal of Antimicrobial Agents. 2005; 26: 343-356.

19. Bona EAM, Pinto, FGS, Borges AMC, Weber LD, Fruet TK, Alves LFA, Moura AC.Avaliação da Atividade Antimicrobiana de Erva-Mate (Ilex paraguariensis) sobre Sorovares de Salmonella spp. de Origem Avícola. Ciência Biológica e da Saúde. 2010; 12 (3): 45-48.

20. Girolometto G, Avancini CAM, Carvalho HHC, Wiest JM. Atividade antibacteriana de extratos de ervamate (Ilex paraguariensis A.St.-Hil.). Revista Brasileira de Plantas Medicinais. 2009; 11 (1): 49-55.

21. Gonçalves AL, Alves Filho A, Menezes H. Estudo comparativo da atividade antimicrobiana de extratos de algumas árvores nativas. Arquivos do Instituto Biológico . 2005; 72 (3): 353-358.

22. Burris K P, Davidson PM, Stewart C N, Harte Jr FM. Antimicrobial activity of yerba mate (Ilex paraguariensis) aqueous extracts against Escherichia coli O157:H7 and Staphylococcus aureus. Journal of Food Science. 2011; 76 (6): 456-462.

23. Silva N, Junqueira VCA, Silveira NFA, Taniwaki MH, Santos RFS, Gomes RAR. Manual de Métodos de análise microbiológica de alimentos e água. 4.ed.- Livraria Varela: São Paulo, 2010, 624p.

24. Brasil. Ministério da Agricultura Pecuária e Abastecimento. Instrução Normativa no. 62 de 26 de agosto de 2003. Resolve oficializar os métodos analíticos oficiais para análises microbiológicas para controle de produtos de origem animal e água. Diário Oficial da União. 2003 Set 18. Português.

25. Vaquero MJR, Serravalle, LRT, Nadra, MCM, Saad, AMS. Antioxidant capacity and antibacterial activity of phenolic compounds from argentinean herbs infusions. Food Control. 2010; 21: 779-785.

26. Carelli G, Macedo SMD, Valduga AT, Corazza ML, Oliveira JV, Ranceschi E, Vidal R, Jaskulski MR. Avaliação preliminar da atividade antimicrobiana do extrato de erva-mate (Ilex paraguariensis A. St. - Hil.) obtido por extração com $\mathrm{CO}_{2}$ supercrítico. Revista Brasileira de Plantas Medicinais. 2011; 13 (1): 110-115.

27. Asolini FC, Tedesco AM, Carpes ST, Ferraz C, Alencar SM. Atividade antioxidante e bacteriana dos compostos fenólicos dos extratos de plantas usadas como chás. Brazilian Journal of Food Technology. 2006; 9(3): 209-215.

28. Schirmer BC, Langsrud S. Evaluation of Natural Antimicrobials on Typical Meat Spoilage Bacteria In Vitro and in Vacuum-Packed Pork Meat. Journal of Food Science. 2010; 75 (2): 98-102.

29. Racanicci AMC, Allesen-holm BH, Skibsted LH. Sensory evaluation of precooked chicken meat with mate (Ilex paraguariensis) added as antioxidant. European Food Research Technology. 2009; 229: 277-280. 